\title{
A case of natural queen succession in a captive colony of naked mole-rats, Heterocephalus glaber
}

\author{
L.A. van der Westhuizen', J.U.M. Jarvis' \& N.C. Bennett ${ }^{2 *}$ \\ ${ }^{1}$ Department of Zoology, University of Cape Town, Rondebosch, Cape Town, 7700 South Africa \\ ${ }^{2}$ Mammal Research Institute, Department of Zoology \& Entomology, University of Pretoria, \\ Pretoria, 0002 South Africa \\ Received 20 December 2012. Accepted 5 March 2013
}

\begin{abstract}
Naked mole-rats occur in large colonies where usually a single queen monopolizes reproduction. Queen succession occurs from within usually as a result of aggressive encounters with subordinate females that queue for reproductive succession following colony instability, which inevitably results in death of either the queen or the challenging conspecific. We monitored a queen succession following the death of the breeding male in a colony of the naked mole-rat, Heterocephalus glaber, prior to, during as well as after replacement of the original breeding female. The response of the pituitary luteotrophs was investigated in the non-reproductive females during this period of instability by the administration of endogenous gonadotrophin releasing hormone (GnRH) and evaluating the subsequent luteinising hormone (LH) response in the blood. Larger and older non-breeding females engaged in aggressive encounters that culminated in death. The new breeding successor which arose from within the colony was a large female who continued to procreate. The six non-breeding females that were killed during reproductive takeover were larger and older females which exhibited elevated basal circulating LH concentrations as well as increased pituitary sensitivity as measured by the amount of releasable $\mathrm{LH}$ to an exogenous GnRH challenge. By contrast, non-breeding females that survived the succession were smaller and younger animals with reduced basal and GnRH challenged LH concentrations. Likewise, five non-breeding males which were heavier and older than those non-breeding males which survived were killed. These animals did not, however, show elevated basal or exogenous GnRH challenged LH concentrations when compared to the surviving males. The non-breeding animals of both sexes which survived the reproductive takeover event represented individuals which posed a minimal threat to the new successor and hence promoted the continuation of the marked reproductive skew that is prevalent in this highly inbred colonial subterranean hystricomorph.
\end{abstract}

Key words: naked mole-rat, Heterocephalus glaber, luteinizing hormone, queen, reproductive replacement, succession.

\section{INTRODUCTION}

The naked mole-rat, Heterocephalus glaber, inhabits the arid regions of East Africa in colonies typically containing around 70 animals (Brett 1991). The colonies are characterized by a primary reproductive division of labour, whereby one female and between one and three male consorts are reproductively active (Jarvis 1981, 1991). Other colony members are reproductively suppressed and are responsible for varying degrees of burrow maintenance activities (Jarvis 1981; Jarvis et al. 1991; Lacey \& Sherman 1991). Indeed, the naked mole-rat exhibits possibly the most extreme form of socially induced infertility or reproductive suppression currently described in any vertebrate (for review see Faulkes \& Abbott 1997). Although non-reproductive mole-rats remain reproductively inactive

\footnotetext{
^Author for correspondence. E-mail: ncbennett@zoology.up.ac.za
}

while in the presence of the breeding female, they undergo rapid reproductive activation if housed singly (Faulkes 1990; Faulkes et al. 1990).

Queen succession is not a common event within the laboratory and we know little about queen succession in the wild. Upon the death of the breeding female in the colony, several nonbreeding females from within the colony may simultaneously become reproductively active, with the eventual result that only one new breeding female will arise from this event. A number of such successions have been reported (Jarvis 1991; Lacey \& Sherman 1991; Margulis et al. 1995; Clarke \& Faulkes 1997). However, to date no study has looked at the endocrinological changes which take place before, during and after a succession. Queen succession may be rapid or it may be drawn out for more than a year. It is invariably accompanied by 
intense aggression and the resultant deaths of several individuals. In contrast, male-male competition over reproductive opportunities is weak or absent (Clarke \& Faulkes 1998).

Although reproduction is usually monopolized by a single breeding female (Jarvis 1981, 1991), the occasional presence of a temporary second reproductive female (Jarvis 1991; Sherman et al. 1992) provides evidence that non-breeding females are not all equally suppressed to the same degree. It has been found that close to parturition, when the breeding female is very gravid, her control on the non-breeders appears to weaken as indicated by increased concentrations of urinary oestradiol $17 \beta$ and opening of vaginal closure membranes in certain non-breeding females close to parturition (Westlin et al. 1994). Nearly all natural deaths of queens occur when they are heavily gravid (Jarvis 1991). It is postulated that the relaxation of reproductive suppression in a select few non-breeders may ensure that the breeding animal is rapidly replaced if she dies (Jarvis 1991).

Clarke \& Faulkes (1997) found that dominance position of a female is a good indicator of reproductive status, the breeding female usually being succeeded by the next highest ranking female, but this is not always the case. However, other studies have manipulated colonies by removing breeders (Clarke \& Faulkes 1997) or have not investigated in detail queen succession (Jarvis 1991).

In this study, we have capitalized on a natural queen takeover event in the laboratory and investigated in detail the endocrinological changes which arise amongst potential 'new' breeders and those animals that remain suppressed prior to and after the queen's death.

\section{MATERIALS \& METHODS}

\section{The study colony}

The naked mole-rat colony chosen for this study was selected on the basis of its long-term behavioural history documented by O'Riain (1996). The colony was initiated from a breeding pair in 1987 and prior to the takeover event in August 1995 constituted 34 animals of which 18 were female. The breeding male had died 48 days prior to disruption within the colony and was probably the trigger to the takeover event. A few days after giving birth, the breeding female was wounded by a non-breeding female (no. 27) towards whom she had previously displayed aggressive behaviour during late pregnancy and a few days post-partum. A takeover event occurred during which seven females (including the breeding female), as well as five males were killed (Table 1). Following the takeover event three males, nos 9, 11 and 20, were the only males to engage in ano-genital nuzzling with the new breeding female (no. 28). This behaviour is very characteristic of reproductive males and hence in this study these three males were considered 'putative breeding males'. After the takeover event the colony consisted of 13 males and 11 females.

\section{Housing and feeding of naked mole-rats}

The colony was housed in an artificial Perspex burrow system comprised of approximately $3.5 \mathrm{~m}$ Perspex transparent tubing $(4.5 \mathrm{~cm}$ wide $\times 5.3 \mathrm{~cm}$ high), with a removable lid, connected to four chambers which served as a nest, food chamber and two latrines. The containers were covered with glass lids, which facilitated easy observation of the

Table 1. Details of the animals that were killed, and the dates of their respective deaths.

\begin{tabular}{cccccc}
\hline Animal & Sex & Mass & Litter & Date died & Days after initial fighting \\
\hline 14 & F & 57.5 & 3 & 1 Sep 95 & 16 \\
23 & F & 54.4 & 5 & 10 Sep 95 & 25 \\
25 & M & 47.5 & 5 & 14 Sep 95 & 29 \\
26 & M & 60.5 & 5 & 16 Sep 95 & 31 \\
4 & BF & N/A & 1 & 19 Sep 95 & 34 \\
27 & F & 55.9 & 5 & 19 Sep 95 & 34 \\
31 & F & 51.5 & 6 & 20 Sep 95 & 35 \\
36 & F & 39.8 & 7 & 27 Sep 95 & 42 \\
29 & M & 43.3 & 6 & 2 Oct 95 & 47 \\
30 & F & 46.6 & 6 & 3 Oct 95 & 48 \\
35 & M & 37.9 & 7 & 18 Oct 95 & 63 \\
34 & M & 42.5 & 7 & 25 Oct 95 & 70 \\
\hline
\end{tabular}

$\mathrm{F}=$ female, $\mathrm{M}=$ male, $\mathrm{BF}=$ breeding female. 
animals. The animals were held in a room kept on a continuous dull light regime, a temperature of $30^{\circ} \mathrm{C}$ and a relative humidity of $50 \%$. Shredded paper towelling was provided as nesting material and the floors of the tunnel and chambers were covered with wood shavings. The toilet areas and food chamber was cleaned daily.

The mole-rats were fed a variety of fresh fruits and vegetables, all of which had been cleaned in a solution of Biocide ${ }^{\mathrm{TM}}$ to prevent the introduction of pathogenic bacteria into the colonies. The mole-rats were fed daily and occasionally the colony was provided with a small amount of hydrated ProNutro ${ }^{\mathrm{TM}}$, a high protein breakfast cereal. Mole-rats obtain all of their water requirements from their food and consequently no free water was provided.

To facilitate identification, each mole-rat was numbered on its back with a black felt-tipped permanent marker. The marking usually lasted for about five days. Data were collected prior to and after a reproductive takeover event in the colony.

\section{Behavioural observations}

All behavioural observations were collected using the Psion organizer (Psion, U.K.) on which the Observer was installed. The Observer ${ }^{\mathrm{TM}}$, a software package for behavioural recording and analysing developed by Noldus Information Technology (Wageningen, the Netherlands), was used to score the behavioural acts. Data were recorded prior to reproductive takeover, during the period of late pregnancy and again following parturition for two days prior to the initial fighting. In total, $13 \mathrm{~h}$ of behavioural data were recorded as a series of $30 \mathrm{~min}$ and $1 \mathrm{~h}$ focal samples on the breeding female (Altmann 1974). Sexual and agonistic behaviours were recorded ad libitum. Agonistic encounters included: 1) biting, where the teeth of one animal cover the body of the other. 2) Shoving, where two animals face each other with their heads touching and one animal pushes the other backwards. 3) Sparring where animals face one another and lock with their incisors. Furthermore, a further 17 hours of behavioural observation was carried out over a period of two weeks following the onset of fighting at $30 \mathrm{~min}$ and $1 \mathrm{~h}$ focal samples. All behavioural data were recorded between 09:00 and 17:00.

\section{Blood sampling}

Blood samples were collected, prior to and after administration of $0.1 \mu \mathrm{g} \mathrm{GnRH}$, from all animals above $26 \mathrm{~g}$ in body mass, except the queen, who had already been killed. Exogenous GnRH administration is given to investigate the degree of LH manufacture and storage in the luteotrophs of the pituitary. Blood samples were collected prior to and after GnRH administration following reproductive takeover on all surviving colony members.

To obtain blood, animals were hand-held and a clearly visible superficial vein on the hind or fore foot was pricked with a 22-gauge hypodermic needle. Blood $(80 \mu \mathrm{l})$, was collected by capillary action using heparinized micro-haematocrit tubes with 2-6 tubes filled per bleed. There was no evidence of tissue damage 1-2 days following bleeding of an animal. The blood was centrifuged at 3000 r.p.m for $10 \mathrm{~min}$ and the plasma stored at $-70^{\circ} \mathrm{C}$ (Bennett et al. 1993).

\section{GnRH administration}

The GnRH was synthesized in the laboratory of R.P. Millar at the MRC Regulatory Peptides Research Unit at the University of Cape Town. The purity of the GnRH was $>98 \%$ homogeneity (Millar et al. 1987). Following an initial blood collection, a $0.1 \mu$ l dose of GnRH was administered subcutaneously as a single $200 \mu \mathrm{l}$ bolus injection. A further blood sample was then taken 20 min later from each animal

\section{Luteinizing hormone bioassay}

Luteinizing hormone $(\mathrm{LH})$ was measured using an in vitro bioassay based on the production of testosterone by dispersed mouse Leydig cells (Van Damme et al. 1974) as previously described in the naked mole-rat (Faulkes et al. 1990). Details of the assay have been described by Harlow et al. (1984), Hodges et al. (1987) and Bennett et al. (1996, 1997). Plasma samples were assayed in duplicate at a dilution of 1:20 and 1:40 as a routine check for parallelism and compared to the human LH pituitary preparation (2nd International Standard 1988, code no. 80/552 NIBSC, Hertfordshire, England) over the range 360-1.4 $\mu \mathrm{iu} \mathrm{ml} / 100 \mu \mathrm{l}$. The testosterone produced was measured by radioimmunoassay as described by Bennett (1994). Checks for parallelism to the standard curve were also carried out to validate the LH bioassay for plasma taken from animals after GnRH treatment. The curve was parallel to and not significantly different from the reference preparation.

The sensitivity of the assay (determined at the 95\% binding) was $14.4 \mu \mathrm{iu} /$ tube, which is 


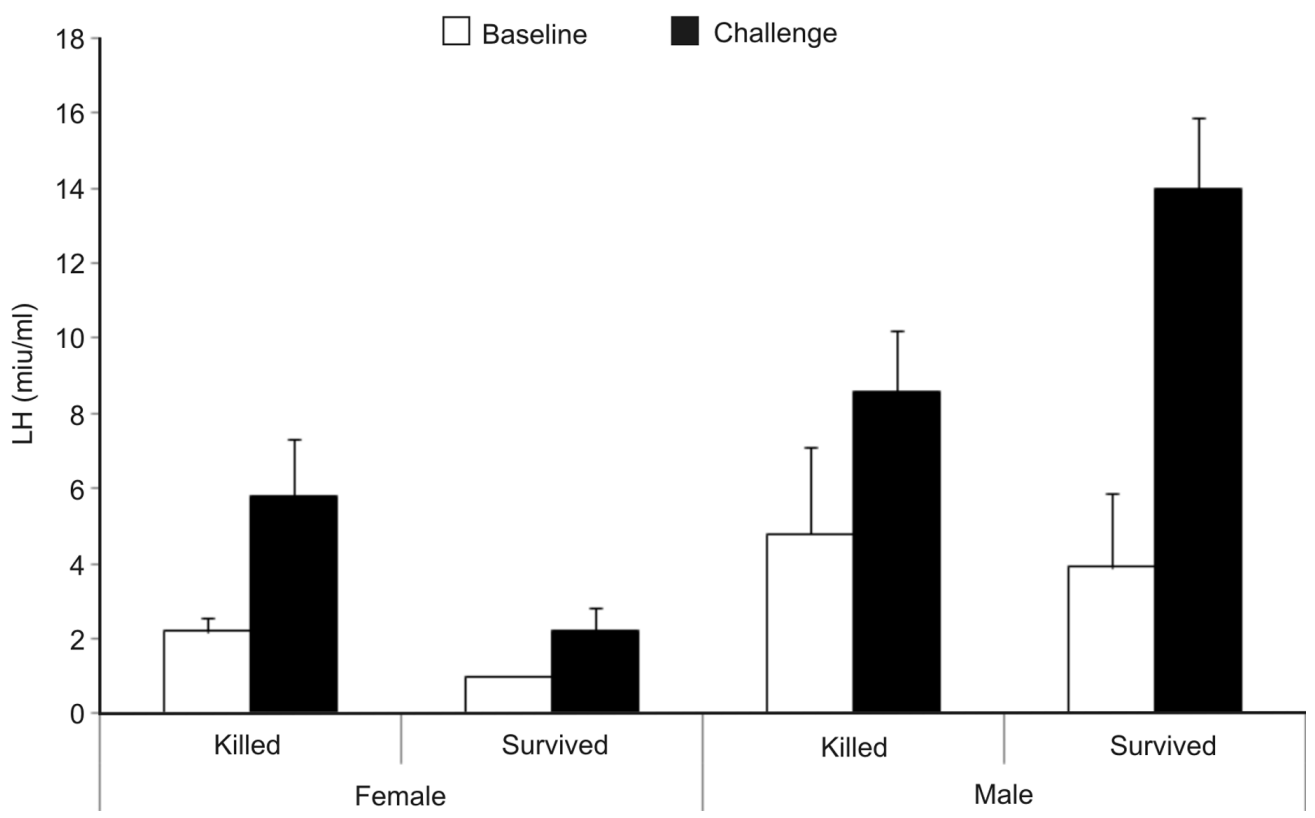

Fig. 1. Basal plasma LH concentrations and the response to a $\mathrm{GnRH}$ challenge (mean \pm S.E.M.) of those nonbreeding female and male mole-rats either killed or surviving the queen takeover event.

equivalent to $2.8 \mathrm{miu} / \mathrm{ml}$. All standard curves for assays were fitted with the program Curvefit 1.2 (Macintosh). Intra and inter-assay coefficient of variation for repeated determinations of a quality control were 10.7 and $17 \%$, respectively.

\section{RESULTS}

\section{Body mass and circulating LH} concentrations in females

The body mass of non-breeding female naked mole-rats that were killed were significantly greater than those that were not (mean \pm S.D. $=$ $51 \pm 2.7 \mathrm{~g}, n=6(36 \pm 3.0 \mathrm{~g}, n=11)(U=58,0.005<$ $P<0.01$; Mann Whitney $U$-test).

The basal concentrations of bioactive LH of those non-breeding female mole-rats that were killed $(2.2 \pm 0.34 \mathrm{miu} / \mathrm{ml}, n=6)$ was significantly greater than those that were not $(1.0 \pm 0.0 \mathrm{miu} / \mathrm{ml}$, $n=6)(U=33, P=0.01$; Mann Whitney $U$-test). Likewise, post-GnRH challenged LH concentrations were greater in those that were killed (5.8 \pm $1.5 \mathrm{miu} / \mathrm{ml}, n=6)$ than those not $(2.2 \pm 0.6 \mathrm{miu} / \mathrm{ml}$, $n=6)(U=29, P>0.05)$ (Fig. 1).

\section{Body mass and circulating LH concentrations in males}

The body mass of the non-breeding males that were killed (mean \pm S.D. $=46 \pm 3.9 \mathrm{~g}, n=5$ ) were significantly higher than those of the nonbreeding males that were not killed $(36 \pm 2.6 \mathrm{~g}, n=$ 5) $(U=30, P=0.025$; Mann, Whitney $U$-test). However, the killed males were significantly lower than that of the putative breeding males $(63.2 \pm 6.3 \mathrm{~g}, n=3)(U=14, P=0.05$; Mann Whitney $U$-test).

The basal bioactive LH concentrations of the non-breeding males killed during the takeover event (mean + S.D. $=4.8 \pm 2.3 \mathrm{miu} / \mathrm{ml}, n=5$ ) were not significantly different from those of the non-breeding males that were not killed $(3.9 \pm 2.0$ $\mathrm{miu} / \mathrm{ml}, n=7)(U=18, P>0.1$; Mann Whitney $U$-test) nor from those of the putative males $(12.7 \pm 6.3 \mathrm{miu} / \mathrm{ml}, n=3 ; U=11.5, P>0.1)$ (Fig. 1$)$

Post-GnRH stimulated plasma LH concentrations were significantly lower in killed males (mean \pm S.D. $=8.6 \pm 1.6 \mathrm{miu} / \mathrm{ml}, n=5)$ than in the non-breeding males that were not killed (14.0 \pm $1.9 \mathrm{miu} / \mathrm{ml})(U=29, P=0.05$; Mann Whitney $U$-test) (Fig. 1).

\section{Behavioural interactions initiated by the breeding female (prior to reproductive takeover)}

\section{Females}

Prior to the takeover event, four of the six non-breeding females received agonistic interac- 
tions from the breeding female. Three of these females (nos 14, 23 and 27) were subsequently killed in the takeover event, whilst the fourth animal became the new breeding female (no. 28). No agonistic interactions were observed between the breeding female and any of the other non-breeding females.

\section{Males}

The breeding female directed agonistic interactions towards all three putative breeding males (nos 9, 11 and 20) and three of the non-breeding males (nos 49, 26 and 29).

Male no. 26 received $61.5 \%(n=13)$ of the total queen aggression initiated towards males and received $20 \%$ of the breeding female's agonistic interactions $(n=40)$. Both non-breeding males nos 26 and 29 were killed in the reproductive takeover.

The primary recipients of the sexual interactions (ano-genital nuzzling) initiated by the breeding female were the three putative breeding males (nos 9, 11 and 20 who received 28.9, 34.6 and $32.7 \%$ of sexual interactions, respectively).

The only non-breeding male to initiate any sexual interactions towards the breeding female was no. 26, who was observed nuzzling her genitals once, and the only males to regularly initiate sexual interactions towards the breeding female were the putative breeding males nos $11 \& 20$, who were responsible for $58 \%$ and $29 \%$ of the total sexual interactions initiated towards the breeding female respectively.

\section{Behavioural interactions during the reproductive takeover}

\section{Females}

Prior to reproductive takeover, which coincided with late pregnancy, the breeding female began to display heightened aggression towards female no. 27 , the third largest female in the colony. Non-breeding female no. 27 did not retaliate when attacked, but rather adopted a submissive posture.

Post-partum, the attacks on female no. 27 became heightened and more vicious, the frequency changing from 2.1 attacks/h prior to parturition (10 h observation) increasing to around 8.0 attacks/h after parturition ( $3 \mathrm{~h}$ observation). Three days post-partum, both no. 27 and the breeding female exhibited severe injuries, in the form of deep puncture wounds.

One week after the initial fighting had broken out, female no. 27 became the most dominant animal in the colony. She was involved in far more interactions in the colony than previously recorded and exhibited behaviours characteristic of the breeding female. She patrolled the burrow system and regularly attacked the breeding female. Female no. 14 then started to attack no. 27.

Sixteen days after the initial fight between the breeding female no. 4 and female no. 27, female no. 14 was killed. Nine days later nonbreeding female no. 23 was killed. In the following two weeks non-breeding female no. 28 emerged as the most dominant animal in the colony and began to initiate frequent attacks on the three oldest and largest non-breeding females in the colony (nos 30, 31 and 36). The five non-breeding males (nos 25, 26, 29, 34 and 35), which were killed during reproductive takeover, were seen to engage in frequent sexual encounters with each other and non-breeding female no. 31.

Both the breeding female no. 4 and non-breeding female no. 27 died 34 days after the initial fighting had broken out. The following day no. 31 was found dead. Female no. 36, was killed seven days later. Female no. 28 directed her attacks against male nos 29 and 30, both being killed within seven days of each other.

Female no. 28 became the new breeding female 49 days after the initial outbreak of fighting. She gave birth 84 days after the death of her last rival (female no. 30). Although no more females were killed; a further two non-breeding males (nos 34 and 35) were killed within a month of the outbreak of fighting. It was uncertain who had killed them. The chronology of the killings is presented in Table 1.

\section{DISCUSSION}

The factors which trigger a reproductive takeover in naked mole-rat colonies, where a subordinate non-breeding female challenges the supremacy of the breeding female's reproductive status are unknown. The levels of aggression displayed by breeding females are variable (Jarvis 1991). Assuming that breeding females do in fact use agonistic interactions to maintain reproductive suppression in non-breeders, it is possible that if a breeding female displays a high level of aggressive behaviour, it may indicate that she has less control over her colony than more placid breeding females have over their respective colonies, and therefore have to continuously exert dominance in order to maintain control.

It is possible that the death of the breeding male 
may sometimes act as a trigger for takeover events. Indeed, the breeding male had died 48 days prior to the commencement of takeover. It is of interest that the previous takeover event in this colony had occurred seven months earlier and had also coincided with the death of the original breeding male.

Previously reported cases of natural takeover events in captive colonies of naked mole-rats have not considered the role of the breeding male, probably because of the difficulty in identifying them. Margulis et al. (1995) removed both the breeding male and female within a colony in order to investigate breeding female succession. They assumed that the removal of the breeding female alone was the overriding factor that governed the subsequent takeover event. In this study the breeding male died from the injuries sustained from intercolonial fighting resulting from the escape of an individual from a neighbouring colony into the study colony. The invading male may have possibly brought about the activation of several breeding females. Jarvis (1991) and Westlin et al. (1994) have shown that the breeding female is most vulnerable to takeover when she is highly gravid just prior to parturition. Interestingly, in this case, the reproductive takeover began only three days after parturition and when the queen had begun to display aggressive behaviour.

Non-breeding female naked mole-rats are capable of becoming reproductively active within a relatively short time of being removed from the colony (Faulkes 1990; Faulkes et al. 1990). However, since all non-breeding females have the potential of becoming breeders, the question arises, what determines whether an individual becomes involved in aggressive interactions with the queen and who eventually takes over as the new queen? In most instances of natural succession in the laboratory, involving the death of the breeding female, it is the oldest or largest female in the colony that becomes the new reproductive (Jarvis 1991; O'Riain 1996). Under experimental conditions, Clarke \& Faulkes (1997) have shown that those females which succeed as the new reproductive in addition to being the oldest and heaviest are usually the most dominant. Margulis et al. (1995) found that following the removal of the breeding pair, the female that eventually emerged as the new breeding female was not the largest, but the oldest. However, Lacey \& Sherman (1991) demonstrated that the breeders are not necessarily the oldest animals in the colony.

In the present study, non-breeding females that were killed during reproductive takeover were both older and heavier than those which were not killed. Female no. 28, who became the new breeder, was the heaviest, but not the oldest female. It is of interest that female no. 28 only became involved in fighting once the three oldest females had been killed (nos 14, 23 and 27).

Interestingly, prior to the takeover event, all the females that survived, including no. 28 , had very low basal plasma LH concentrations. However, all females that were killed had higher circulating basal LH concentrations. The mean plasma LH of those females that were killed $(2.2 \pm 0.3 \mathrm{miu} / \mathrm{ml}$; $n=6$ ) were higher than previously measured plasma LH concentrations from non-breeding females $(1.6 \pm 0.1 \mathrm{miu} / \mathrm{ml} ; n=57)$. Furthermore, the mean GnRH stimulated plasma LH concentration of the non-breeding females that were killed $(5.8 \pm 1.5 \mathrm{miu} / \mathrm{ml}, n=6)$ in addition to being higher than those of the non-breeding females that survived, were also higher than those previously measured in non-breeding females (2.9 \pm $0.5 \mathrm{miu} / \mathrm{ml}$ ) measured prior to a succession (Faulkes et al. 1990). These slightly elevated basal plasma LH concentrations and the greater pituitary sensitivity to exogenous GnRH in the non-breeding females suggest that there was a degree of reproductive relaxation in these females prior to reproductive takeover.

The death of non-breeding males during reproductive takeover was unexpected, since they were not involved in competition over breeding status. Three males in the colony were seen to engage in ano-genital nuzzling with the original breeding female, so called putative breeding males which survived the ordeal. Jarvis (1991) has suggested that when males are killed by the breeding female it may be the result of them showing increased sexuality but they are not however, closely bonded to the breeding female. In such a case they would represent a threat to the breeding female by mating with perforate non-breeding females when she is heavily gravid and unable to exert her dominance effectively (Jarvis 1991). Clarke \& Faulkes (1997) have reported the deaths of four non-breeding males following the removal of the breeding female from the colony. These males had been four of the most dominant males in the colony prior to the planned removal and post mortem examination showed the reproductive tracts to be full of sperm.

In this study, five non-breeding males were killed in the course of the reproductive takeover. 
These five males, apart from the three putative breeding males were amongst the heaviest and oldest non-breeding males. However, it is uncertain why these males were killed since their hormone profiles, unlike the non-breeding females that were killed, did not exhibit a greater circulation basal LH concentration than those which survived. In addition they exhibited a reduced pituitary sensitivity to an exogenous GnRH challenge. It is in the interests of the breeding female to actively maintain suppression of reproduction of non-breeding animals even during a period of apparent stability in a colony, in order to retain reproductive supremacy. This is achieved by aggressive shoving bouts, directed towards animals that pose a threat. It would thus appear that the breeding female directs her aggression towards the older colony members. Indeed, O'Riain (1996) found that the adult colony members are usually the primary recipients of aggressive interactions such as shoving, whereas juveniles are rarely if ever shoved. He also reported that those individuals that are never shoved show no signs of sexual activity following the death or removal of breeders, whereas those individuals that are frequently shoved are usually the first to show external signs of reproductive activity. The common factor to all the animals (both male and female) that were killed during the course of the reproductive takeover event was that they were all the offspring of the original breeding pair and therefore the oldest colony members.

There is a great deal of variability in both the time taken for colony succession to be completed, in addition to the levels of aggression accompanying successions. Jarvis (1991) found that when the colony structure has been heavily disrupted, by for example the removal of the queen, colony succession is almost always accompanied by fierce fighting. Margulis et al. (1995) reported that it took 67 days before another non-breeding female challenged the breeding female which had taken over as dominant following the removal of the original breeding female. Clarke \& Faulkes (1997) on the other hand had colonies in which breeding began 54-65 days after queen removal, while a third colony did not exhibit reproductive activation until after nearly 20 months following queen removal.

The maintenance of reproductive skew is an important component of naked mole-rat sociality. It is postulated that the non-breeding animals of both sexes which survived the reproductive take- over event represented individuals which posed minimal threat to the new successor and hence promoted the continuation of the marked reproductive skew that is prevalent in this highly inbred colonial subterranean hystricomorph.

\section{ACKNOWLEDGEMENTS}

The authors thank R.P. Millar, Department of Chemical Pathology, University of Cape Town, for donating the mammalian GnRH. We also thank the National Institute of Biological Standards and Control, Hertfordshire, England, for the LH pituitary preparation (2nd International Standard 1988 , code 80/552). The work was supported by research grants from the then Foundation for Research Development (to N.C.B. and J.U.M.J.), the University of Pretoria (to N.C.B.) and the University of Cape Town (to J.U.M.J). This study was approved by the Animal Ethics Committee of the University of Cape Town

\section{REFERENCES}

ALATMANN, J. 1974. Observational study of behaviour: sampling methods. Behaviour 49: 227-267.

BENNETT, N.C. 1994. Reproductive suppression in social Cryptomys damarensis colonies - a lifetime of socially-induced sterility in males and females. Journal of Zoology, London 219: 45-59.

BENNETT, N.C. FAULKES, C.G. \& MOLTENO, A.J. 1996. Reproductive suppression in subordinate, nonbreeding female Damaraland mole-rats: two components to a lifetime of socially induced infertility. Proceedings of the Royal Society of London, Biological Sciences 263: 1599-1603.

BENNETT, N.C., FAULKES, C.G. \& SPINKS, A.C. 1997. $\mathrm{LH}$ responses to single doses of exogenous GnRH by social Mashona mole-rats: a continuum of sociallyinduced infertility in the family Bathyergidae. Proceedings of the Royal Society of London Biological Sciences 264: 1001-1006.

BENNETT, N.C., JARVIS, J.U.M., FAULKES, C.G. \& MILLAR, R.P. 1993. LH responses to single doses of exogenous GnRH by freshly captured Damaraland mole-rats, Cryptomys damarensis. Journal of Reproduction and Fertility 99: 81-96.

BRETT, R.A. 1991. The population structure of naked mole-rat colonies. In: The Biology of the Naked Mole-rat, (eds) P.W. Sherman, J.U.M. Jarvis \& R. Alexander, pp. 137-184. Princeton University Press, Princeton.

CLARKE, F.M. \& FAULKES, C.G. 1997. Dominance and queen succession in captive colonies of the eusocial naked mole-rat, Heterocephalus glaber. Proceedings of the Royal Society of London, Biological Sciences 264: 993-1000.

CLARKE, F.M. \& FAULKES, C.G. 1998. Hormonal and behavioural correlates of male dominance and reproductive status in captive colonies of the naked mole-rat, Heterocephalus glaber. Proceedings of the Royal Society of London, Biological Sciences 265: 1391-1399. 
FAULKES, C.G. \&ABBOTT, D.H. 1997. The physiology of reproductive dictatorship: regulation of male and female reproduction by a single breeding female in colonies of naked mole-rats. In: Cooperative Breeding in Mammals, (ed.) N.G. Solomon \& J.A. French, pp. 302-334. Cambridge University Press, Cambridge and New York.

FAULKES, C.G. 1990. Social suppression of reproduction in the naked mole-rat, Heterocephalus glaber. Ph.D. thesis, University of London, London.

FAULKES, C.G., ABBOTT, D.H., JARVIS, J.U.M. \& SHERRIFF, F.E 1990. LH responses of female naked mole-rats, Heterocephalus glaber, to single and multiple doses of exogenous GnRH. Journal of Reproduction and Fertility 89: 317-323.

HARLOW, C.R., GEMS, S., HODGES, J.K. \& HEARN, J.P. 1984. The relationship between plasma progesterone and the timing of ovulation and early embryonic development in the marmoset monkey (Callithrix jacchus). Journal of Zoology, London 201: 272-282.

HODGES, J.K., COTTINGHAM, P., SUMMERS, P.M. \& YINGNAN, L. 1987. Controlled ovulation in the marmoset monkey (Callithrix jacchus) with human chorionic gonadotrophin following prostaglandin induced luteal regression. Fertility and Sterility 48: 299-305.

JARVIS, J.U.M. 1981. Eusociality in a mammal: cooperative breeding in naked mole-rat colonies. Science 212: 571-573.

JARVIS, J.U.M. 1991. Reproduction of naked mole-rats. In: The Biology of the Naked Mole-rat, (eds) P.W. Sherman, J.U.M. Jarvis \& R. Alexander, pp. 384-425. Princeton University Press. Princeton.

JARVIS, J.U.M., O'RIAIN, M.J. \& McDAID, E. 1991. Growth and factors affecting body size in naked mole-rats. In: The Biology of the Naked Mole-rat, (eds)
P.W. Sherman, J.U.M. Jarvis \& R. Alexander, pp. 258-383. Princeton University Press, Princeton.

LACEY, E.A. \& SHERMAN, P.W. 1991. Social organization of naked mole-rat colonies: evidence for divisions of labor. In: The Biology of the Naked Mole-rat, (eds) P.W. Sherman, J.U.M. Jarvis \& R.D. Alexander, pp. 209242. Princeton University Press, Princeton.

MARGULIS, S.W., SALTZMAN, M. \& ABBOTT, D.H. 1995. Behavioural and hormonal changes in female naked mole-rats (Heterocephalus glaber) following removal of the breeding female from a colony. Hormones $\mathcal{E}$ Behaviour 29: 227-247.

MILLAR, R.P., FLANAGAN, C.A, MILTON, R.C. \& KING J.A. 1989. Chimeric analogues of vertebrate gonadotrophin releasing hormones comprising substitutions of the variant amino acids in positions 5 , 7 and 8. Journal of Biological Chemistry. 264: 2100721013.

O'RIAIN, M.J. 1996. Pup ontogeny and factors influencing behavioural and morphological variation in naked mole-rats, Heterocephalus glaber (Rodentia, Bathyergidae). PhD thesis, University of Cape Town, Cape Town.

SHERMAN, P.W., JARVIS, J.U.M. \& BRAUDE, S.H. 1992. Naked mole-rats. Scientific American 267(2): 72-78.

VAN DAMME, M-P., ROBERTSON, D.M. \& DICZFALUSY, E. 1974. An improved in vitro bioassay method for measuring luteinizing hormone (LH) activity using mouse Leydig cell preparations. Acta Endocrinology Copenhagen 77: 655-671.

WESTLIN, L.M., BENNETT, N.C. \& JARVIS, J.U.M. 1994. Relaxation of reproductive suppression in nonbreeding female naked mole-rats, Heterocephalus glaber. Journal of Zoology, London 234: 177-188.

Responsible Editor. J.H van Wyk 